\title{
TH588, an MTH1 inhibitor, enhances phenethyl isothiocyanate-induced growth inhibition in pancreatic cancer cells
}

\author{
FUMIYOSHI IKEJIRI $^{1}$, YOSHIO HONMA ${ }^{1,2}$, TAKASHI KASUKABE ${ }^{3}$, TAKESHI URANO ${ }^{2}$ and JUNJI SUZUMIYA ${ }^{1}$ \\ The Departments of ${ }^{1}$ Oncology/Hematology, ${ }^{2}$ Biochemistry and ${ }^{3}$ Medical Education and Research, \\ Faculty of Medicine, Shimane University, Izumo, Shimane 693-8501, Japan
}

Received April 20, 2017; Accepted December 13, 2017

DOI: $10.3892 / \mathrm{ol} .2017 .7713$

\begin{abstract}
Chemotherapy and radiotherapy are the most common approaches in cancer therapy. They may kill cancer cells through the generation of high levels of reactive oxygen species (ROS), which leads to oxidative DNA damage. However, tumor resistance to ROS is a problem in cancer therapy. MTH1 sanitizes oxidized dNTP pools to prevent the incorporation of damaged bases during DNA replication. Although MTH1 is non-essential in normal cells, cancer cells require MTH1 activity to avoid the incorporation of oxidized dNTPs, which would result in DNA damage and cell death. By targeting a redox-adaptation mechanism, MTH1 inhibition represents a novel therapeutic strategy against cancer. However, recent reports have indicated that growth inhibition by MTH1 inhibitors may be due to off-target cytotoxic effects. TH588, one of the first-in-class MTH1 inhibitors, kills cancer cells by an off-target effect. However, a low concentration of TH588 may effectively inhibit MTH1 activity without inhibiting cell proliferation. Phenethyl isothiocyanate (PEITC) is a dietary anticarcinogenic compound and an inducer of ROS. In the present study, it has been demonstrated that combined treatment with PEITC and TH588 effectively inhibited the growth of pancreatic cancer MIAPaCa-2 and Panc-1 cells. The antioxidant $\mathrm{N}$-acetylcysteine negated this synergistic growth inhibition. PEITC and TH588 cooperatively induced the formation of 8-oxo-deoxyguanine in nuclei and $\mathrm{pH} 2 \mathrm{AX}$ foci, a marker of DNA damage. However, the combined effects are not associated with MTH1 mRNA expression in several cancer cell lines, suggesting that the possibility of an off-target effect of TH588 cannot be eliminated. These results suggest that the combination of PEITC and TH588 has potential as a novel therapeutic strategy against pancreatic cancer.
\end{abstract}

Correspondence to: Professor Yoshio Honma, Department of Oncology/Hematology, Faculty of Medicine, Shimane University, 89-1 Enya, Izumo, Shimane 693-8501, Japan

E-mail: biohonma@med.shimane-u.ac.jp

Key words: MTH1, TH588, phenethyl isothiocyanate, ROS inducer, oxidative DNA damage, pancreatic cancer cells

\section{Introduction}

Pancreatic cancer remains a highly lethal neoplasm. Even with multimodality therapy for localized disease, patient survival is measured in months. Although the FOLFIRINOX regimen has produced substantial benefits in the treatment of metastatic pancreatic cancer, it is associated with severe adverse effects (1). The further development of better therapeutic regimens for pancreatic cancer requires new and potent anticancer agents.

Ras transformation renders cells sensitive to reactive oxygen species (ROS)-induced cell death $(2,3)$, and pancreatic cancers exhibit an extremely high mutation rate of K-ras (>90\%) (4). Therefore, we investigated the anti-proliferative effects of ROS generators on pancreatic cancer cells. Phenethyl isothiocyanate (PEITC) is a potent ROS generator (5-8). PEITC belongs to the family of natural isothiocyanates, which are found in a variety of cruciferous vegetables and released when the vegetables are cut or masticated (5). PEITC has an inhibitory effect on the growth of several types of cancer cells, and is now being studied in phase 2 clinical trials for the prevention of lung and oral cancer $(3,5-8)$. ROS results in the oxidation of cell constituents such as DNA, lipids and proteins, and this oxidation may damage cancer cells and ultimately lead to cell death.

ROS attack nucleotides present in the deoxynucleoside triphosphate (dNTP) pool as well as within DNA, and convert them into their oxidized forms. The dNTP used in DNA synthesis are up to 13,000-fold more susceptible to oxidative damage than bases in duplex DNA (9). MuT homolog-1 (MTH1) is a pyrophosphatase that acts on oxidized nucleotides and hydrolyzes 8-oxo-2'-deoxyguanosine triphosphate in the dNTP pool to prevent its incorporation into nuclear and mitochondrial DNA, which reduces cytotoxicity in cells $(10,11)$.

MTH1 is overexpressed in cancer cells and prevents oxidized nucleotides from being misincorporated into DNA. Although MTH1 is non-essential in normal cells, cancer cells require MTH1 activity to avoid the incorporation of oxidized dNTPs, which would result in DNA damage and cell death (12-14). By aiming at a redox-adaptation mechanism, MTH1 inhibition represents a new approach for a therapeutic strategy against cancer $(15,16)$. However, recent reports have indicated that growth inhibition by MTH1 inhibitors may be due to off-target cytotoxic effects $(17,18)$. TH588 is a potent inhibitor of human 
MTH1 with an $\mathrm{IC}_{50}$ value of $5 \mathrm{nM}$ and inhibits the growth of cancer cell lines $\left(\mathrm{IC}_{50} \mathrm{~s}=2.48-6.37 \mu \mathrm{M}\right)$ without significant cytotoxicity toward immortalized cells $\left(\mathrm{IC}_{50} \mathrm{~s} \geq 20 \mu \mathrm{M}\right)$ (17). It exhibits $>1000$-fold selectivity for MTH1 over the related Nudix hydrolase protein family members MTH2, NUDT5, NUDT12, NUDT14, and NUDT16, as well as other proteins with known nucleoside triphosphate pyrophosphatase activity (dCTPase, dUTPase, and ITPA) (17). These results suggest that low concentrations of MTH1 inhibitors may suppress the enzyme activity without anti-proliferative activity. TH588 has good metabolic stability and is available in vivo (17). In the present study, we examined the combined effects of TH588 and PEITC on the growth of human pancreatic cancer cells.

\section{Materials and methods}

Materials. TH588 was obtained from Selleckchem (Houston, TX, USA). PEITC and 3-(4,5-dimethyl-2-thiazolyl)2,5-diphenyltetrazolium bromide (MTT) were purchased from Sigma-Aldrich; Merck KGaA, Darmstadt, Germany. General caspase inhibitor benzyloxycarbonyl-Val-Ala-Asp-fluoromethylketone (Z-VAD-FMK) was purchased from R\&D Systems, Inc., Minneapolis, MN, USA.

Cells and cell culture. Human pancreatic carcinoma (MIAPaCa-2 and Panc-1), lymphoma (BALM3), and leukemia (NB4) cells were cultured in RPMI 1640 medium supplemented with $10 \%$ fetal bovine serum and $80 \mu \mathrm{g} / \mathrm{ml}$ gentamicin at $37^{\circ} \mathrm{C}$ in a humidified atmosphere of $5 \% \mathrm{CO}_{2}$ in air.

Assay of cell growth and viability. Cell numbers were counted in a Model Z1 Coulter Counter (Beckman Coulter, Tokyo, Japan). The cells were seeded at $1 \times 10^{5}$ cells $/ \mathrm{ml}$ in a $24-$ well multidish. After culture with or without the test compounds for the indicated times, viable cells were examined by a modified MTT assay (19) or a trypan blue dye exclusion test using an automated cell counter (Bio-Rad Laboratories, Inc., Hercules, CA, USA).

Reverse transcription-quantitative polymerase chain reaction (RT-qPCR). Total RNA was extracted from cells using TRI reagent (Sigma-Aldrich; Merck KGaA). Total RNA was converted to first-strand cDNA primed with random hexamer in a reaction volume of $20 \mu \mathrm{l}$ using an RNA PCR kit (qPCR RT Master Mix; Toyobo Life Science, Osaka, Japan), and $2 \mu 1$ of this reaction was used as a template in real time PCR. The primers were used as described previously (20). The RT-qPCR reaction was performed using an Takara TP860 Real-Time PCR system (Takara Bio Inc., Tokyo, Japan) according to the manufacture's instruction. The threshold cycle values were normalized to the threshold value of glyceraldehydes-3-phosphate dehydrogenase. Real-time PCR results were calculated according to the following protocol: Relative expression level $=2^{-\Delta \mathrm{Ct}}$, where $\Delta \mathrm{Cq}=\mathrm{Cq}$ (gene of interest)-Cq (housekeeping gene) (20).

Immunofluorescence microscopy. Cells were fixed with $4 \%$ paraformaldehyde in PBS for $10 \mathrm{~min}$ at room temperature, and then permeabilized with $0.3 \%$ Tween-20 for $15 \mathrm{~min}$. After fixation, cells were washed three times with PBS and then blocked with blocking buffer ( $1 \%$ bovine serum albumin in
PBS for 60 min. Cells were incubated with anti-pH2AX (Cell Signaling Technology Inc., Tokyo, Japan) for $60 \mathrm{~min}$, washed with the blocking buffer and then incubated for 60 min with Alexa Fluor 594-conjugated anti-rabbit secondary antibodies (Cell Signaling Technology Inc.) and FITC-labeled avidin (Vector Laboratories, Inc., Burlingame, CA, USA). Avidin binds with high specificity to 8 -oxo-dG $(21,22)$. Confocal images were obtained using an inverted microscope (Olympus Corporation, Tokyo, Japan). All immunofluorescence experiments were repeated three times.

Statistical analysis. The results are expressed as means \pm standard deviation (SD). Pairs of data were compared using Student's t-test. Significant differences were considered to exist for probabilities below $5 \%(\mathrm{P}<0.05)$ and are indicated by asterisks (*). For comparisons among multiple groups, an F-test using one-way analysis of variance and a post hoc Tukey-Kramer test were performed to demonstrate statistical significance. Again, significant differences were considered to exist for probabilities below $5 \%$.

\section{Results}

Combined effects of TH588 and ROS-inducers on the growth of MIAPaCa-2 cells. The potent MTH1 inhibitor TH588 concentration-dependently inhibited the growth of pancreatic cancer Panc-1 cells, but the antioxidant $\mathrm{N}$-acetyl cysteine (NAC) did not affect the growth inhibition (Fig. 1A), suggesting that the growth inhibition induced by TH588 is independent of oxidized stress. These results are consistent with reports that growth inhibition by TH588 may be due to off-target cytotoxic effects $(17,18)$. However, it is possible that TH588 may act as an MTH1 inhibitor under oxidized stress conditions for cytotoxic effects. Thus, we examined the effect of TH588 on the growth of Panc-1 cells in the presence of hydrogen peroxide $\left(\mathrm{H}_{2} \mathrm{O}_{2}\right)$. A low concentration of TH588 alone did not affect cell growth, but significantly enhanced $\mathrm{H}_{2} \mathrm{O}_{2}$-induced growth inhibition (Fig. 1B). Next, we examined the combined effects of TH588 and ROS inducers. A low concentration of TH588 effectively enhanced the growth inhibition of MIAPaCa-2 cells induced by several ROS inducers, such as doxorubicin (23), MK615 (Japanese apricot extract) (24), isopentenyl adenosine (25) and isothiocyanates (3,5-8). Combined treatment with doxorubicin and TH588 effectively inhibited the growth of MIAPaCa-2 cells (Fig. 1C). Among them, the combination of PEITC and TH588 was the best for inhibiting the growth of MIAPaCa-2 cells (Fig. 1D). Similar results were obtained when other pancreatic cancer cells were examined. TH588 at $1 \mu \mathrm{M}$ alone hardly affected the grow th of MIAPaCa-2 cells, but significantly enhanced the growth inhibition induced by PEITC (Fig. 1D). NAC effectively counteracted the growth inhibition induced by PEITC alone (Fig. 2A), as well as that by PEITC plus TH588 (Fig. 2B). These results suggest that ROS production is associated with the growth-inhibitory effects of TH588 plus ROS inducers. When the cells were treated with $4 \mu \mathrm{M}$ PEITC and $2 \mu \mathrm{M}$ TH588, the viability was markedly decreased and it was significantly counteracted with the general caspase inhibitor Z-VAD-FMK (Fig. 2C), suggesting that the combined treatment induced caspase-dependent cell death. As shown in Fig. 2D, MTH1 mRNA is expressed in 

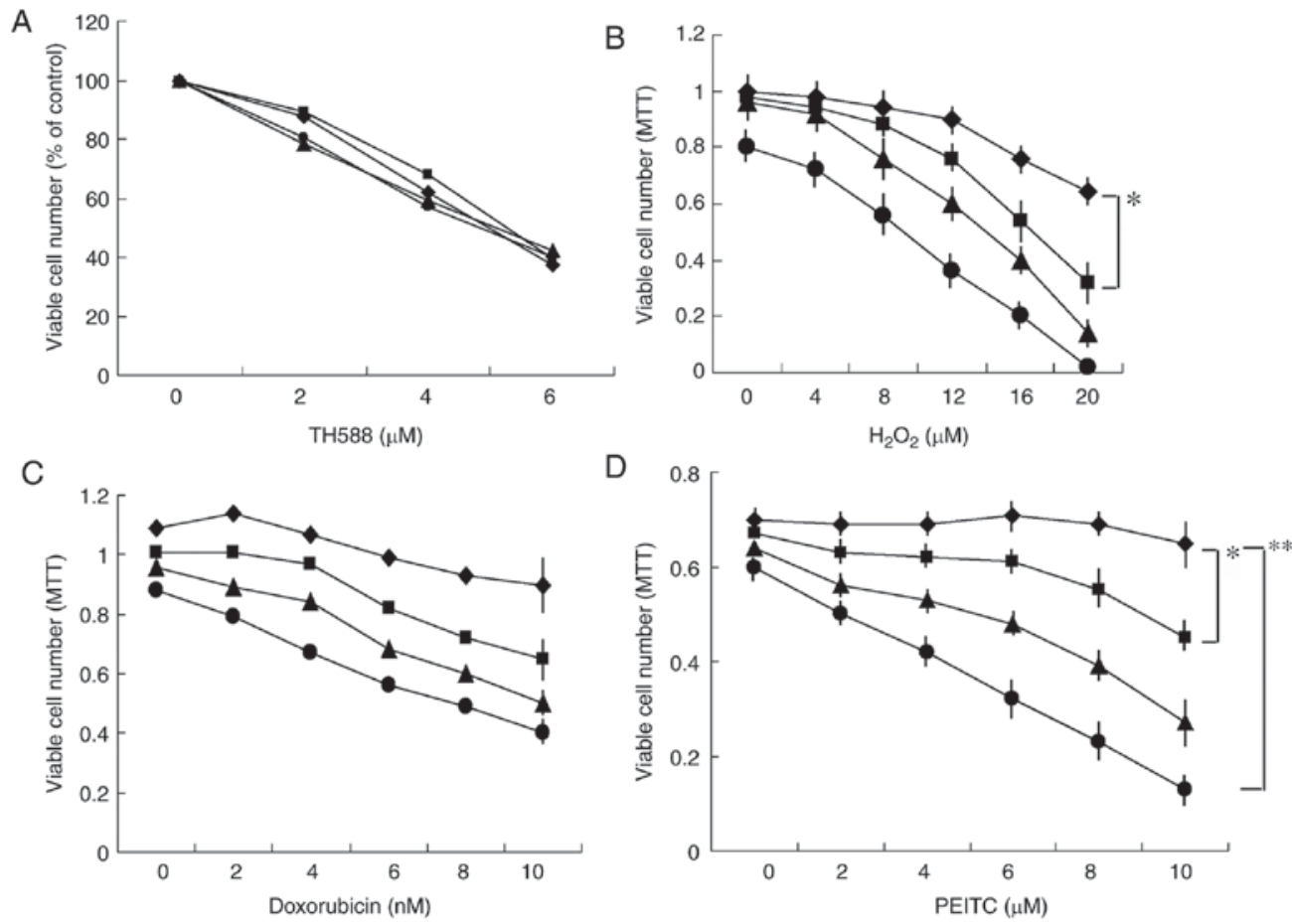

Figure 1. (A) Effect of NAC on the growth-inhibitory effect of TH588. Panc-1 cells were cultured with TH588 in the presence of $0(\bullet), 5(\bullet), 7.5(\mathbf{\Delta})$, or $10(\bullet)$ mM NAC for 5 days. The values are the means of 3 determinations. (B) Combined effects of $\mathrm{H}_{2} \mathrm{O}_{2}$ and TH588 on growth of Panc-1 cells. Cells were treated with $\mathrm{H}_{2} \mathrm{O}_{2}$ in the presence of $0(\bullet), 1(\bullet), 2(\boldsymbol{\Delta})$, or $3(\bullet) \mu \mathrm{M}$ TH588 for 7 days. $\mathrm{H}_{2} \mathrm{O}_{2}$ was added on days 0,3 and 5 . The values are the means $\pm \mathrm{SD}$ of 3 determinations. (C and D) Combined effects of TH588 and doxorubicin or PEITC on growth of MIAPaCa-2 cells. Cells were treated with doxorubicin (C) or PEITC (D) in the presence of $0(\bullet), 1(\bullet), 2(\boldsymbol{\Delta})$, or $3(\bullet) \mu \mathrm{M}$ TH588 for 5 days. The values are the means \pm SD of 3 determinations. ${ }^{*} \mathrm{P}<0.05,{ }^{* *} \mathrm{P}<0.01$.
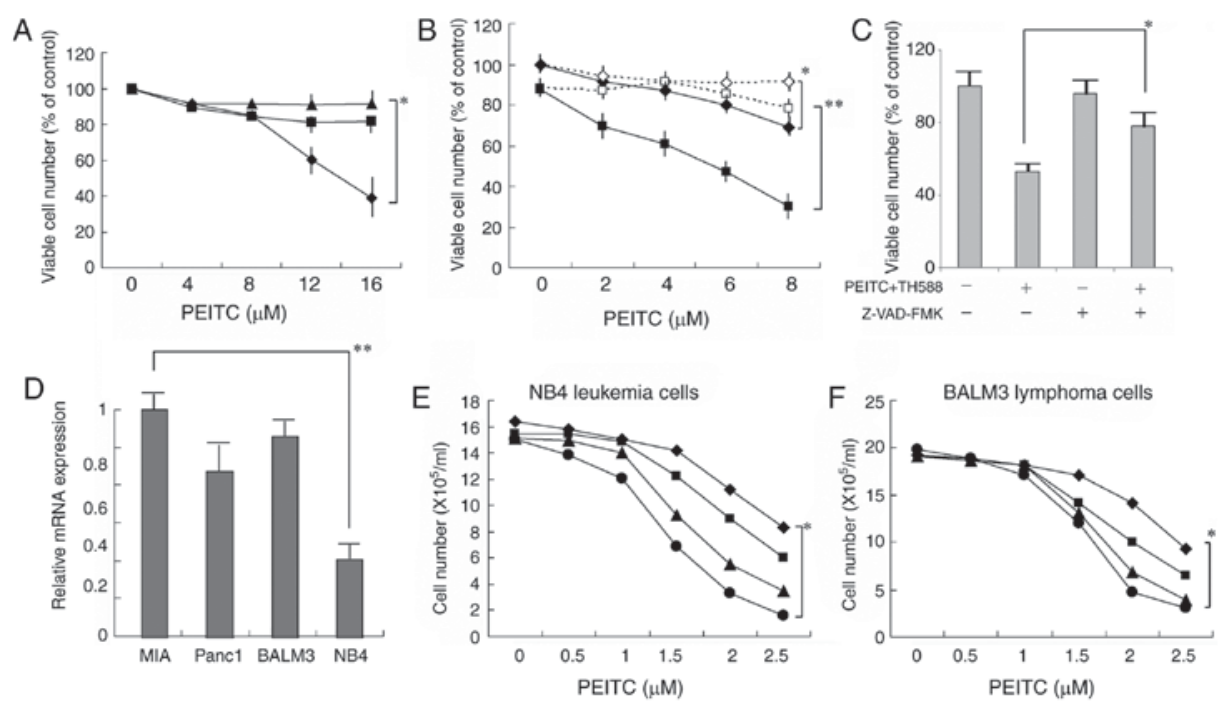

Figure 2. (A) Effect of NAC on the growth-inhibitory effect of PEITC. MIAPaCa-2 cells cultured with PEITC in the presence of $0(\bullet), 5(\mathbf{\bullet})$, or $7.5(\mathbf{\Lambda}) \mathrm{mM}$ NAC for 6 days. The values are the means \pm SD of 3 determinations. (B) Effect of NAC on the growth-inhibitory effect of PEITC plus TH588. MIAPaCa-2 cells cultured with PEITC $(\bullet, \diamond)$ or PEITC plus $2 \mu \mathrm{M}$ TH588 $(\mathbf{\square}, \square)$ in the presence $(\diamond, \square)$ or absence $(\bullet, \mathbf{\bullet})$ of $7.5 \mathrm{mM}$ NAC for 6 days. The values are the means \pm SD of 3 determinations. (C) Suppression by caspase inhibitor of the cell death induced by PEITC and TH588. Cells were treated with $4 \mu \mathrm{M}$ PEITC plus $2 \mu \mathrm{M}$ TH588 in the presence of $4 \mu \mathrm{M} \mathrm{Z-VAD-FMK} \mathrm{for} 2$ days. The values are means of three separate experiments \pm SD. (D) MTH1 mRNA expression in several cancer cell lines. Gene expression was determined by RT-PCR and normalized to MIAPaCa-2 cells. The values are means of three separate experiments \pm SD. (E, F) Combined effects of PEITC and TH588 on the growth of leukemia or lymphoma cells. Cells were treated with PEITC in the presence of $0(\bullet), 0.2(\mathbf{\bullet}), 0.4(\mathbf{\Lambda})$, or $0.6(\bullet) \mu \mathrm{M}$ TH588 for 5 days. The values are the means of 3 determinations. ${ }^{*} \mathrm{P}<0.05,{ }^{* *} \mathrm{P}<0.01$.

several malignant cell lines. The combined treatment was also effective in leukemia and lymphoma cells (Fig. 2E and F). Although expression of MTH1 mRNA in NB4 leukemia cells was less than $35 \%$ in MIAPaCa-2 cells, the combined treatment similarly effective to NB4 cells.
Enhancement of the formation of 8-oxo- $d G$ and DNA damage by combined treatment with TH588 and PEITC. MIAPaCa-2 cells treated with $2 \mu \mathrm{M}$ TH588 exhibited increases in both a marker of DNA damage, the phosphorylation of histone 2A.X (pH2AX), and the formation of 8-oxo-dG (Fig. 3A). Both 
A

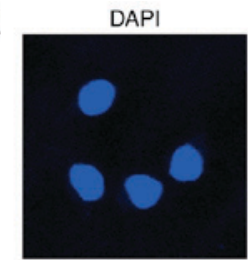

B
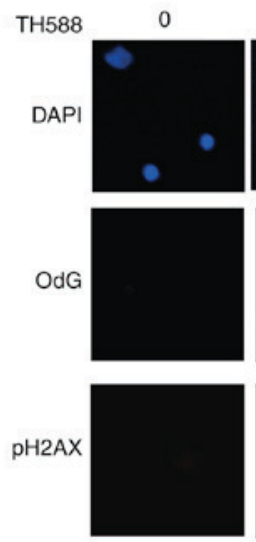

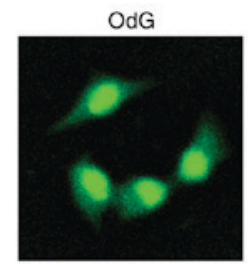

0.4
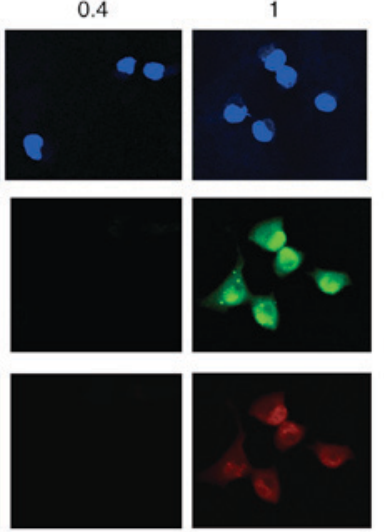

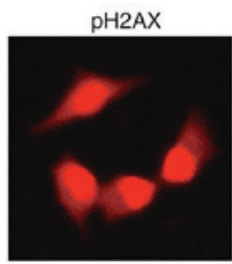

C PEITC 0
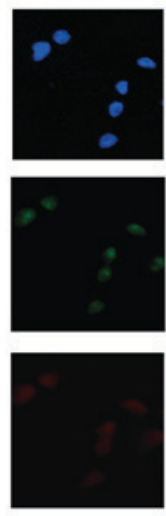
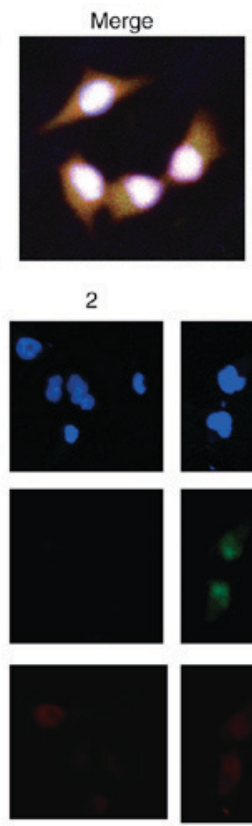

4
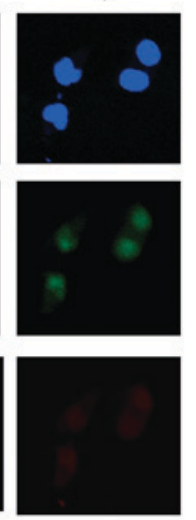

Figure 3. (A) Nuclear accumulation of 8-oxo-dG and pH2AX in the cells treated with TH588. MIAPaCa- 2 cells were treated with $2 \mu \mathrm{M}$ TH588 for 56 hrs. ( $\mathrm{B}$ and $\mathrm{C}$ ) Induction of 8-oxo-dG and pH2AX in MIAPaCa-2 cells by TH588 (B) or PEITC (C) for 56 h. Representative microscopic images (A; 800 , B and $\mathrm{C}$; magnification, $\mathrm{x} 400$ ) of 3 independent experiments. OdG, 8-oxo-dG.

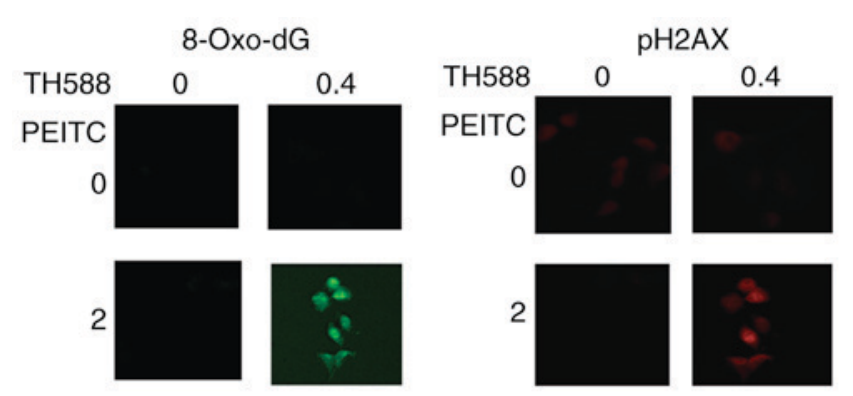

Figure 4. Combined effects of PEITC and TH588 on the formation of 8-oxo-dG and $\mathrm{pH} 2 \mathrm{AX}$ foci in MIAPaCa-2 cells. Cells were treated with or without $0.4 \mu \mathrm{M}$ TH588 in the presence or absence of $2 \mu \mathrm{M}$ PEITC for $56 \mathrm{~h}$. Representative microscopic images (magnification, $\mathrm{x} 400$ ) of 3 independent experiments.

of these effects were mainly localized in nuclei. Although TH588 at $1 \mu \mathrm{M}$ hardly affected the growth of MIAPaCa-2 cells (Fig. 1A), formation of 8-oxo-dG and $\mathrm{pH} 2 \mathrm{AX}$ was evident in treatment for $56 \mathrm{~h}$ (Fig. 3B), suggesting that TH588 enhances 8-oxo-dG production. PEITC also concentration-dependently induced the formation of 8-oxo-dG, and this effect was evident in the treatment with $4 \mu \mathrm{M}$ (Fig. 3C). These results indicate that 8 -oxo-dG formation and DNA damage were induced by low concentrations of TH588 or PEITC, which hardly affected the growth of MIAPaCa-2 cells. Fig. 4 shows that low concentrations of TH588 and PEITC co-operatively induce the formation of 8-oxo- $\mathrm{dG}$ and DNA damage in MIAPaCa-2 cells. Similar results were observed in Panc-1 cells treated with TH588 and PEITC.

\section{Discussion}

While the mechanism of the anticancer activity of isothiocyanates has not yet been fully elucidated, numerous pathways have been implicated. They include oxidative stress, cell cycle arrest, inhibition of histone deacetylation, inhibition of angiogenesis, and regulation of translation initiation (5). PEITC disables the glutathione antioxidant system and causes ROS accumulation preferentially in cancer cells (5). In the present investigation, the effect of PEITC was completely counteracted by treatment with NAC (Fig. 2A), suggesting that the effects were mainly due to oxidative stress by ROS generation. One of the mechanisms that protects cancer cells from the cytotoxic effect of high levels of ROS is the expression of MTH1, which sanitizes oxidized dNTP pools by converting them to the corresponding monophosphates $(10,11)$. TH588 is a potent and selective inhibitor of human MTH1, although the growth-inhibiting effect of TH588 is not associated with the inhibition of MTH1 $(17,18)$. While MTH1 function may be critical to survival in cells with elevated levels of ROS, MTH1 is dispensable in cancer cells under normal culture conditions. Wang et al (26) reported that the sensitivity of melanoma cells to TH588 is correlated with the level of endogenous ROS, although the cytotoxicity of TH588 is not associated with its inhibitory effect on MTH1. In the present study, TH588 enhanced the formation of 8 -oxo-dG induced by PEITC (Fig. 4). These results suggest that TH588 enhances the formation of 8-oxo-dG in DNA and contributes to growth inhibition in cancer cells with highly elevated levels of ROS. However, MTH1 mRNA expression is not associated with the combined effects of TH588 plus PEITC (Fig. 2). We cannot eliminate the possibility that TH588 act the other site(s). These results suggest that the combined treatment indicates the off-target effects, although low concentrations of TH588 enhance the formation of 8-oxo-dG in DNA.

MTH1 is overexpressed in glioblastoma, and MTH1 silencing inhibits colony formation and xenograft tumor growth (27). A high expression of MTH1 was significantly associated with deeper tumor invasion, advanced cancer 
stage, and poor overall survival and disease-specific survival compared with low MTH1 expression on esophageal squamous cell carcinoma (28). These results suggest that MTH1 may be a potential target for cancer therapy, although MTH1 is dispensable for some malignancies. Further investigation will be necessary to understand the role of MTH1 in cancer therapy.

Since several reports have shown that PEITC has little toxic effects on normal cells (5), oxidative stress caused by PEITC can be used to treat drug-resistant cancer cells. However, there is no evident dose-relationship between the cellular ROS level and its cytotoxicity in cancer cells treated with several ROS inducers (29), suggesting that many factors may influence ROS-mediated cytotoxicity in cancer cells. Lactic acidosis induced a much higher ROS level in cancer cells than PEITC, but permitted the progressive growth of cancer cells (29). PEITC covalently modifies the cysteine side chains of glutathione S-transferase, which irreversibly inhibits its enzymatic activity (30). This irreversible inhibition may contribute to effective cell-killing. The combination of PEITC and TH588 may become a novel therapeutic strategy against cancers.

\section{Acknowledgements}

The present study was supported in part by the SUIGAN project, Shimane University, Japan.

\section{References}

1. Conroy T, Desseigne F, Ychou M, Bouché O, Guimbaud R, Bécouarn Y, Adenis A, Raoul JL, Gourgou-Bourgade S, de la Fouchardière $\mathrm{C}$, et al: FOLFIRINOX versus gemcitabine for metastatic pancreatic cancer. N Engl J Med 364: 1817-1825, 2011.

2. Shaw AT, Winslow MM, Magendantz M, Ouyang C, Dowdle J, Subramanian A, Lewis TA, Maglathin RL, Tolliday N and Jacks T: Selective killing of K-ras mutant cancer cells by small molecule inducers of oxidative stress. Proc Natl Acad Sci USA 108: 8773-8778, 2011

3. Trachootham D, Zhou Y, Zhang H, Demizu Y, Chen Z, Pelicano H, Chiao PJ, Achanta G, Arlinghaus RB, Liu J and Huang P: Selective killing of oncogenically transformed cells through a ROS-mediated mechanism by beta-phenylethyl isothiocyanate. Cancer Cell 10: 241-252, 2006.

4. Henzel AF, Kimmelman AC, Stanger BZ, Bardeesy N and Depinho RA: Genetics and biology of pancreatic ductal adenocarcinoma. Genes Dev 20: 1218-1249, 2006.

5. Wu X, Zhou QH and $\mathrm{Xu} \mathrm{K}$ : Are isothiocyanates potential anti-cancer drugs? Acta Pharmacol Sin 30: 501-512, 2009.

6. Wu X, Kassie F and Mersch-Sundermann V: Induction of apoptosis in tumor cells by naturally occurring sulfur-containing compounds. Mutat Res 589: 81-102, 2005.

7. Kasukabe T, Honma Y, Okabe-Kado J, Higuchi Y, Kato N and Kumakura S: Combined treatment with cotylenin A and phenethyl isothiocyanate induces strong antitumor activity mainly through the induction of ferroptotic cell death in human pancreatic cancer cells. Oncol Rep 36: 968-976, 2016.

8. Xiao D, Powolny AA, Moura MB, Kelley EE, Bommareddy A, Kim SH, Hahm ER, Normolle D, Van Houten B and Singh SV: Phenethyl isothiocyanate inhibits oxidative phosphorylation to trigger reactive oxygen species-mediated death of human prostate cancer cells. J Biol Chem 285: 26558-26569, 2010.

9. Topal MD and Baker MS: DNA precursor pool: A significant target for $\mathrm{N}$-methyl-N-nitrosourea in $\mathrm{C} 3 \mathrm{H} / 10 \mathrm{~T} 1 / 2$ clone 8 cells. Proc Natl Acad Sci USA 79: 2211-2215, 1982.

10. Yoshimura D, Sakumi K, Ohno M, Sakai Y, Furuichi M, Iwai S and Nakabeppu Y: An oxidized purine nucleoside triphosphatase, MTH1, suppresses cell death caused by oxidative stress. J Biol Chem 278: 37965-37973, 2003.
11. Sakai Y, Furuichi M, Takahashi M, Mishima M, Iwai S, Shirakawa M and Nakabeppu Y: A molecular basis for the selective recognition of 2-hydroxy-dATP and 8-oxo-dGTP by human MTH1. J Biol Chem 277: 8579-8587, 2002.

12. Kennedy CH, Pass HI and Mitchell JB: Expression of human MutT homologue (hMTH1) protein in primary non-small-cell lung carcinomas and histologically normal surrounding tissue. Free Radic Biol Med 34: 1447-1457, 2003.

13. Giribaldi MG, Munoz A, Halvorsen K, Patel A and Rai P: MTH1 expression is required for effective transformation by oncogenic HRAS. Oncotarget 6: 11519-11529, 2015.

14. Patel A, Burton DG, Halvorsen K, Balkan W, Reiner T, Perez-Stable C, Cohen A, Munoz A, Giribaldi MG, Singh S, et al: MutT homolog 1 (MTH1) maintains multiple KRAS-driven pro-malignant pathways. Oncogene 34: 2586-2596, 2015.

15. Gad H, Koolmeister T, Jemth AS, Eshtad S, Jacques SA, Ström CE, Svensson LM, Schultz N, Lundbäck T, Einarsdottir BO, et al: MTH1 inhibition eradicates cancer by preventing sanitation of the dNTP pool. Nature 508: 215-221, 2014.

16. Huber KV, Salah E, Radic B, Gridling M, Elkins JM, Stukalov A, Jemth AS, Göktürk C, Sanjiv K, Strömberg K, et al: Stereospecific targeting of MTH1 by (S)-crizotinib as an anticancer strategy. Nature 508: 222-227, 2014.

17. Kawamura T, Kawatani M, Muroi M, Kondoh Y, Futamura Y, Aono $\mathrm{H}$, Tanaka M, Honda $\mathrm{K}$ and Osada $\mathrm{H}$ : Proteomic profiling of small-molecule inhibitors reveals dispensability of MTH1 for cancer cell survival. Sci Rep 6: 26521, 2016.

18. Kettle JG, Alwan H, Bista M, Breed J, Davies NL, Eckersley K, Fillery S, Foote KM, Goodwin L, Jones DR, et al: Potent and selective inhibitors of MTH1 probe its role in cancer cell survival. J Med Chem 59: 2346-2361, 2016.

19. Kawakami K, Hattori M, Inoue T, Maruyama Y, Ohkanda J, Kato N, Tongu M, Yamada T, Akimoto M, Takenaga K, et al: A novel fusicoccin derivative preferentially targets hypoxic tumor cells and inhibits tumor growth in xenografts. Anticancer Agents Med Chem 12: 791-800, 2012.

20. Zhang X, Song W, Zhou Y, Mao F, Lin Y, Guan J and Sun Q: Expression and function of MutT homolog 1 in distinct subtypes of breast cancer. Oncol Lett 13: 2161-2168, 2017.

21. Struthers L, Patel R, Clark J and Thomas S: Direct detection of 8-oxodeoxyguanosine and 8-oxoguanine by avidin and its analogues. Anal Biochem 255: 20-31, 1998.

22. Conners R, Hooley E, Clarke AR, Thomas S and Brady R: Recognition of oxidatively modified bases within the biotin-binding site by avidin. J Mol Biol 357: 263-274, 2006.

23. Goodman J and Hochstein P: Generation of free radicals and lipid peroxidation by redox cycling of adriamycin and daunomycin. Biochem Biophys Res Commun 77: 797-803, 1977.

24. Hattori M, Kawakami K, Akimoto M, Takenaga K, Suzumiya J and Honma Y: Antitumor effect of Japanese apricot extract (MK615) on human cancer cells in vitro and in vivo through a reactive oxygen species-dependent mechanism. Tumori 99: 239-248, 2013

25. Ishii Y, Hori Y, Sakai S and Honma Y: Control of differentiation and apoptosis of human myeloid leukemia cells by cytokinins and cytokinin nucleosides, plant redifferentiation-inducing hormones. Cell Growth Differ 13: 19-26, 2002.

26. Wang JY, Jin L, Yan XG, Sherwin S, Farrelly M, Zhang YY, Liu F, Wang CY, Guo ST, Yari H, et al: Reactive oxygen species dictate the apoptotic response of melanoma cells to TH588. J Invest Dermatol 136: 2277-2286, 2016.

27. Tu Y, Wang Z, Wang X, Yang H, Zhang P, Johnson M, Liu N, Liu H, Jin W, Zhang Y and Cui D4: Birth of MTH1 as a therapeutic target for glioblastoma: MTH1 is indispensable for gliomatumorigenesis. Am J Transl Res 8: 2803-2811, 2016.

28. Akiyama S, Saeki H, Nakashima Y, Iimori M, Kitao H, Oki E, Oda Y, Nakabeppu Y, Kakeji Y and Maehara Y: Prognostic impact of MutT homolog-1 expression on esophageal squamous cell carcinoma. Cancer Med 6: 258-266, 2017.

29. Zhu $\mathrm{C}, \mathrm{Hu} \mathrm{W}, \mathrm{Wu} \mathrm{H}$ and $\mathrm{Hu} \mathrm{X}$ : No evident dose-response relationship between cellular ROS level and its cytotoxicity-a paradoxical issue in ROS-based cancer therapy. Sci Rep 4: 5029, 2014.

30. Kumari V, Dyba MA, Holland RJ, Liang YH, Singh SV and Ji X: Irreversible inhibition of glutathione $\mathrm{S}$-transferase by phenethyl isothiocyanate (PEITC), a dietary cancer chemopreventive phytochemical. PLoS One 11: e0163821, 2016. 